how an adult person possessed of critical reason (and the examples analyzed in the dissertation all concern competent adults) may have his capacity for acting and deciding for himself at all undermined by being proffered such information, which is in no wise intended to deceive, coerce, or force him to undertake a certain action.

Is it not rather the case that a person's powers of self-determination are exercised precisely in the face of such information, that is, in deciding how to react to it and what to make of it? It seems to me that the author here is working with an unduly limited concept of self-determination - one that leads her to imagine "conflicts" where there may be none.

DR STEPHEN MOLLER

Philosophy Department, University of Wales at Cardiff

\section{Moral Strangers, Moral Acquaintance, and Moral Friends. Connectedness and its Conditions}

\author{
Erich H Loewy, Albany, N Y, State \\ University of New York Press, 1997, \\ $\mathrm{xii}+251$ pages, US $\$ 18.95$.
}

This book is basically an attack on libertarian political and moral theory, as espoused by Robert Nozick and more particularly by $\mathrm{H}$ T Engelhardt in his Bioethics and Secular Humanism. Although Professor Loewy is himself a professor of bioethics, the present work is a general work of moral and political theory in which issues of medical ethics are mentioned only incidentally. The term "moral strangers" which features in his title is derived from Engelhardt's book. According to Engelhardt, people from different cultural groups are "moral strangers" who may share no ethical presuppositions in common. Reason and religion, Engelhardt thinks, are both unable to provide ethical codes which are persuasive to all. The only thing that everyone has in common is a desire to pursue his or her own way of life as seems best to them, and so the only moral principle which can reasonably be commended to all is respect for everyone's right to be allowed to do just this to the extent that allows a similar right to others. If a government goes beyond this negative principle and imposes obligations to help others positively, for example by taxing the citizens to finance welfare schemes, it interferes unjustifiably with the liberty of those on whom the obligations are imposed.

This is the standard libertarian position. In reply, Loewy concedes that it is neither possible nor desirable to arrive at agreement on all moral issues - except between "moral friends", those who share some particular religious or other outlook. But he maintains that we are all potentially "moral acquaintances", who share far more than is allowed by the minimal ethic of the libertarian. We are therefore able to "craft an ethic" which is far richer in content than libertarianism and which can be found acceptable in one version or another by all. What we all share is a "framework" constituted by what Loewy calls the "existential a prioris": a drive to stay alive, biological needs, social needs, the desire to avoid suffering, a basic sense of logic and the desire to live freely and pursue our own interests. We also share an innate primitive sense of compassion though this can be distorted or crushed. On this shared basis an ethical discussion informed by "rational compassion" can proceed, and in his final chapter Loewy produces suggestions as to how this discussion might go.

The thesis of this book is obviously important, and its treatment is informed by impressive scholarship: there is a good deal of discussion of classic texts, in particular by Kant and Rousseau. But in the end the book is spoilt by a very rambling and repetitive construction and by a tendency to substitute rhetoric for argument. The result is that the main thrust of the argument is obscured. For example, I remained unclear how far Loewy's case against liberalism is really about enlightened self-interest rather than morality, or indeed whether he is arguing that this distinction cannot in the end be drawn. There are rhetorical tricks which might well alienate even a reader sympathetic to the main idea of the book: for example, the repeated use of the phrase "most of us think" rather than "most people think" to introduce any widely-held beliefs which seem to support Loewy's position. The style of writing makes it hard to read, with long paragraphs and very long and awkwardly constructed sentences. Also, some curious mistakes have crept in at some stage of te book's production: for example, the word "truth" instead of "truce" (in the phrases "armed truce" or "unea truce") appears on pages 21 (twic 24 and 181 (twice).

Although Moral Strangers, Mofal Acquaintance, and Moral Friends is n about medical ethics as such, its theme is clearly relevant to the provision $\mathscr{O f}$ health care and it ought, therefore, $\overrightarrow{0}$ have been of general interest readers of this journal. But its defects are such that all in all I cannot recon: mend it.

ELIZABETH TELFE

Department of Philosophu University of Glasggen

\section{Caring: Gender- sensitive Ethics}

Peta Bowden, London and New Yord, Routledge, 1997, 224 pages $£ 40.00 \sum$ hb, £12.99 pb.

In attempting to formulate a "gend sensitive" ethics, Peta Bowden's bo draws on the now extensive literatunge by feminist theorists, notably Carel Gilligan, who have propounded 霖 ethic of care as a moral framewoik distinct from the more convention ethic of justice and rights. Bowden ${ }^{P_{s}}$ theory starts from the premise that caring is an ethically important pră tice which expresses ethically signio. cant ways in which we matter to eakh other (page 1). She contends thet adopting an "ethic of care" promises gender-sensitive corrective to convertional moral theories (page 9). Arguing that grand theorising is inadequate for explicating practical life and the attempts to produce a feminist ethes often fail to resist the universalisiffy and exclusionary habits of modernicin (page 11) her approach aims to unsetle fixed and unitary understandings caring and is grounded in an insist ence on the particularity of differemt

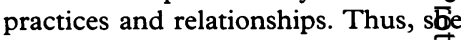
focuses on four contexts - motherin friendship, nursing and citizenship illustrate caring relations.

There is little to dispute in Bo den's contention that caring is generally devalued and that everyday volvement in caring relations rendered invisible. Equally it is di cult to deny her claim that the reflexive nature of caring requires and creates 